\title{
RANCANG BANGUN SEKUENSIAL SWITCHING UNTUK PENGUKURAN GAS KARBON MONOKSIDA (CO) PADA SILO BUNKER DI PLTU UNIT 5 DAN 6 PAITON
}

\author{
Latifah ${ }^{1}$, \\ Program Studi Teknik Elektro Universitas Nurul Jadid \\ Email: lifa4762@gmail.com \\ Amalia Herlina ${ }^{1}$ \\ Program Studi Teknik Elektro Universitas Nurul Jadid \\ Email: amaliaherlina1810@gmail.com \\ Amma Emanihim ${ }^{1}$ \\ Program Studi Teknik Elektro Universitas Nurul Jadid \\ Email: ammaemanihim@gmail.com
}

\begin{abstract}
S : Silo bunker is a place to collect coal from the stock pile which is carried by a conveyor before it is smoothed in the pulverzer or mill. The bunker silo can hold 60 tons of coal. One of the content contained in coal is carbon monoxide gas. Carbon monoxide is a poisonous gas and an explosion can occur if it is indoors. This research designed a switching system for measuring carbon monoxide using a sequential switching concept based on the NOVA sequencer product, namely 402 as Automatic Sequenser using the research and development $(\mathrm{RnD})$ research method, where the design is designed to be useful as a control media and to monitor the amount of carbon monoxide gas content on the bunker silo. The sequential switching design of the PLTU Unit 5 and 6 Paiton based silo bunker was built to control the relay that simulates the circuit breaker $(B)$ function on the 3 way valve solenoid and monitors the carbon monoxide gas content using the MQ-7 sensor. The sensor readings are displayed on the LCD and serial monitor contained in the Arduino IDE application. The sequential switching design of the bunker silo that uses a microcontroller, namely the Arduino Uno R3 Board, is functioning quite well, but the MQ-07 sensor readings often experience error values. As for the 3 way valve solenoid, you must usea compressor to get the pressure on $R$ so that the trigger on the solenoid can work.
\end{abstract}

Keyword: sequential switching, 3 way valve solenoid, silo bunker, MQ-07 sensor, coal.

\begin{abstract}
ABSTRAK: Silo bunker merupakan tempat penampungan batubara dari stock pile yang dibawa oleh konveyor sebelum dihaluskan di pulverizer atau mill. Silo bunker dapat menampung 60 ton batu bara. Kandungan yang terdapat dalam batu bara adalah salah satunya yaitu gas karbon monoksida. Karbon monoksida merupakan gas beracun dan dapat terjadi ledakan apabila dalam ruangan tertutup. Peneliitian ini merancang suatu sistem switching pada pengukuran karbon monoksida dengan menggunakan konsep sekuensial switching berdasarkan produk NOVA sequenser yaitu 402as Otomatis Sequenser dengan menggunakan metode penelitian research and development $(R n D)$, dimana rancang bangun yang dirancang berguna sebagai media control dan monitor besar kandungan gas karbon monoksida pada silo bunker. Perancangan sekuensial switching pada silo bunker PLTU Unit 5 dan 6 Paiton berbasis mikrokontroller dibangun untuk mengontrol relay yang mensimulasikan fungsi circuit breaker $(C B)$ pada solenoid 3 way valve dan memonitor kandungan gas karbon monoksida dengan menggunakan Sensor MQ-7. Adapun hasil pembacaan sensor ditampilkan pada LCD dan serial monitor yang terdapat dalam aplikasi Arduino IDE. Rancang bangun sekuensial switching pada silo bunker yang menggunakan mikrokontroller yaitu boart Arduino Uno R3 yang berfungsi cukup baik, namun pembacaan sensor MQ-7 sering mengalami nilai error. Sedangkan untuk solenoid 3 way valve harus menggunakan kompresor untuk mendapatkan tekanan pada R supaya trigger pada solenoid dapat bekerja.
\end{abstract}

Kata Kunci : Sekuensial Swiching, Selenoid 3 Way Valve, Silo Bunker, Sensor MQ-7, batu bara.

\section{PENDAHULUAN}

$\mathrm{P}$ embangkit Listrik Tenaga Uap (PLTU) Unit 5 dan 6 Paiton dikelola oleh PT YTL Jawa Timur. PLTU menggunakan bahan bakar batu bara untuk menghasilkan listrik. Batu bara tesebut disimpan dalam suatu wadah yaitu silo bunker. Setiap unit memiliki 6 silo bunker, sehingga jumlah silo bunker di unit 5 dan 6 adalah 12 unit.

Batu bara adalah bahan bakar yang terbentuk dari fosil yang terlebih dahulu melewati proses pengendapan dalam tanah. Kandungan yang terdapat dalam unsur batu bara yaitu hydrogen, oksigen, sulfur, karbon dan karbon monoksida. Karbon monoksida merupakan gas yang sangat berbahaya, beracun dan dapat menyebabkan kebakaran[1]. Proses terbentuknya gas CO tidak hanya terjadi secara alami, bisa juga karena hasil gesekan saat transportasi batu bara menuju silo bunker. Kandungan gas CO dalam silo bunker tidak boleh lebih dari 15ppm karena dapat menyebabkan kebakaran bajkan ledakan. Untuk mengantisipasi hal tersebut, maka silo bunker perlu disuntikkan gas $\mathrm{CO} 2$ secara manual.

Kandungan gas CO pada silo bunker D di PT YTL Jawa Timur adalah 32ppm, data tersebut telah dilakukan observasi pada tanggal 09 Januari 2020. Sedangkan batas aman kandungan gas CO pada silo bunker tidak boleh melebihi 15 ppm. Kandungan gas $\mathrm{CO}$ berlebih bisa memicu terjadinya ledakan. Contoh yang terjadi

1 Universitas Nurul Jadid, Karanganyar, Kecamatan Paiton, Kabupaten Probolinggo, Jawa Timur 67292 
kebakaran di PLTU Tanjung Jati terletak pada silo bunker di karenakan kandungan gas CO yang berlebih.[2]

Maka dari itu perlu adanya monitoring kadar gas $\mathrm{CO}$ yang berlebih agar tidak memicu terjadinya kebakaran. Seperti silo bunker dilakukan pengukuran kadar gas CO satu-persatu dari 6 silo bunker setiap unit oleh operator. Berdasarkan fenomena diatas, maka perlu melakukan penelitian di PT YTL Jawa Timur untuk tugas akhir yang berjudul "Rancang Bangun Sekuensial Switching Untuk Pengukuran Gas Karbon Monoksida (CO) Pada Silo Bunker di PLTU Unit 5 dan 6 Paiton". Penelitian tersebut menggunakan mikrokontroller sebagai control switching dengan konsep sekuensial pada silo bunker. Penelitian ini menggunakan metodepenelitian research and development. Di mana research and development yang dibangun berguna sebagai media pengukuran kandungan gas CO dengan switching di setiap silo bunker. Sehingga diharapkan alat ini mampu membantu suatu pekerjaan pengukuran gas CO pada silo bunker supaya dapat membantu operator untuk mengambil sample gas CO pada plant.

\section{METODE PENELITIAN}

Metode penelitian merupakan alur kegiatan yang dilakukan peneliti untuk menyelesaikan sebuah penelitian. Metode yang digunakan dalam penelitian ini adalah dengan metode research and development. Berikut merupakan gambar metode penelitian supaya lebih bisa dipahami.

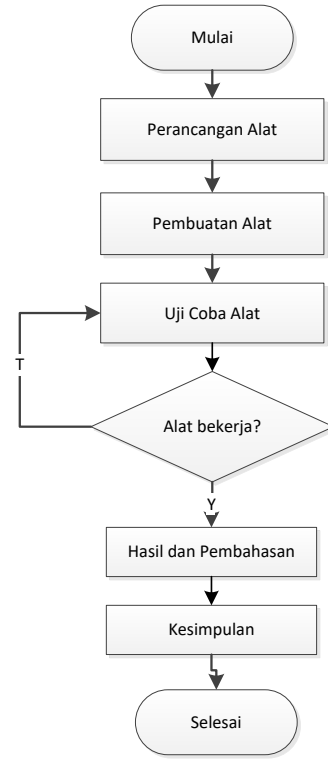

- Gambar 1. Diagram Alir Penelitian

\section{Observasi}

Observasi bertujuan untuk mencari pengetahuan untuk mendapatkan informasi yang dibutukan untuk melakukan penelitian. Pada tahap observasi dengan mengambil data di PLTU Unit 5 dan 6 Paiton yang dilakukan pada tanggal 09 Januari 2020 pada silo bunker $\mathrm{D}$ yang terdapat kandungan gas CO sebesar 32ppm.

2. Studi Literatur

a. 3 way selenoid valve

3 way solenoid valve berfungsi sebagai shut off, releas, mengalirkan atau membuang fluida atau gas. 3 way solenoid valve memiliki 3 port yang terdapat pada body solenoid valve. Berikut blok diagram 3 way solenoid valve.[3]

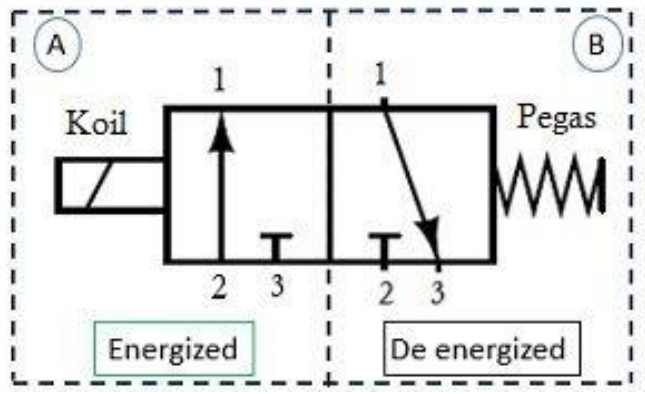

Gambar 2. Diagram 3 Way Selenoid Valve

Ketika solenoid dalam keadaan tidak terhubung dengan sumber tegangan atau pada saat kondisi 
De-energized port-1 terhubung dengan port 3 dan saluran port-1 dengan port-2 akan tertutup dan ketika coil solenoid dihubungkan pada sumber tegangan maka selenoid akan berkondisi energized plunger di dalam body akan berpindah posisi port-1 akan terhubung dengan port-2 sedangkan saluran port-3 akan tertutup.

b. Silo Bunker

Silo bunker merupakan tempat penampungan batubara bara yang nantinya akan diprosessebagai bahan bakar pada sistem pembakaran Pembangkit Listrik Tenaga Uap. Silo bunker dapat menampung 5060 ton batu bara.[4]

c. Sensor MQ-07

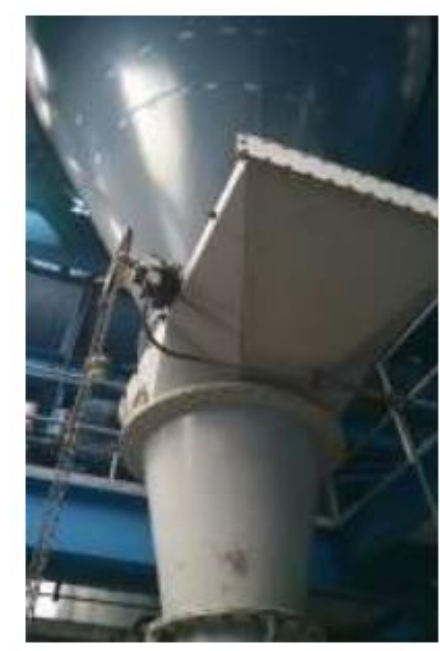

Gambar 3. Silo Bunker

Sensor MQ-07 adalah sensor gas gas karbon monoksida (CO) berfungsi untuk mengetahui konsentrasi gas karbon monoksida. Sensor MQ-07 memiliki sensifitas tinggi dan waktu respon yang cepat. Keluaran yang dihasilkan oleh sensor MQ-07 adalah berupa sinyal analog dan membutuhkan tegangan 5 Direct urrent (DC). Sensor MQ-07 memiliki resistansi (Rs) yang bisa berubah apabila tekanan gas terkontaminasi dengan udara luar. Sensor MQ-07 memerlukan sebuah rangkaian dan pemanas (power heater) sebesar 5V, resistansi beban (load resistance) dan output sensor dihubungkan pada analog to digital converter (ADC), sehingga keluaran dapat ditampilkan kedalam bentuk sinyal digital. Maka nilai digital yang berupa output sensor dapat ditampilkan pada sebuah serial monitor atau alat penampil lainnya. Sensor MQ-07 dapat beroprasi pada suhu $-10^{\circ} \mathrm{C}$ sampai $50^{\circ} \mathrm{C}$ dan mengkonsumsi $<150 \mathrm{~mA}$ pada $5 \mathrm{~V}$. sensor MQ07 memiliki sensifitas yang tinggi, jarak deteksi gas 10-2000ppm gas karbon monoksida, sepon waktu $<150$ detik dan memiliki dimensi $20 \mathrm{~mm}$ diameter, $10 \mathrm{~mm}$ (pin tidak termasuk), $66 \mathrm{~mm}$ tinggi pin.[5]

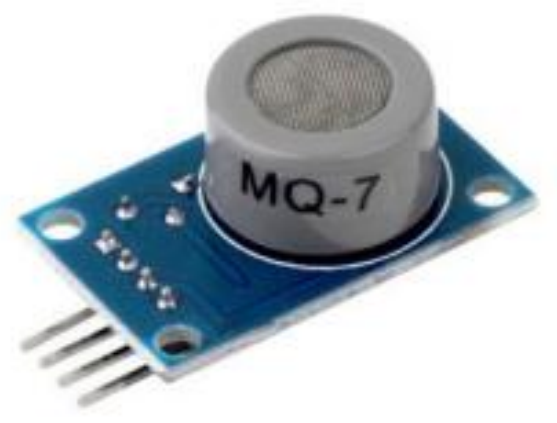

Gambar 4. Sensor MQ-07

d. Tubing

Tubing merupakan komponen yang terbuat dari plastic untuk memindahkan flida (aliran), panas. Pada umumnya tubing digunakan sebagai konektor. Tubing pada umumnya betektur karet, padat, lentur dan memiliki variasi ukuran diameter yaitu, 1/4, 1/2, 3/8, 5/8, 3/4, 7/8, 1, 11/4,11/2, dan 2 in. [6] 


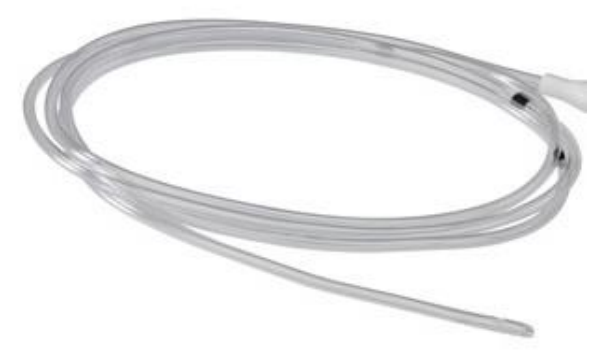

e. Arduino Uno

口ambar 5. Tubing

Arduino adalah papan arduino yang menggunakan mikrokontroller ATMega328. Arduino Uno memiliki 14pindigital (6 pin yang dapat digunakan sebagai output PWM), 6 input analog, sebuah $16 \mathrm{MHz}$ osilator Kristal, sebuah koneksi USB, sebuah konektor sumber tegangan, sebuah header ICSP dan sebuah tombol reset. Arduino Uno memuat segala hal yang dibutuhkan untuk mendukung sebuah mikrokontroller. Hanya dengan meghubungkkan ke sebuah computer melalui USB atau memberikan tegangan DC dari batrai atau adaptor AC ke DC sudah dapat membuatnya bekerja. Arduino uno menggunakan ATmega $16 \mathrm{U} 2$ yang deprogram sebagai $U S B$-to-serial converter untuk komunikasi serial ke computer melalui port USB.[7]

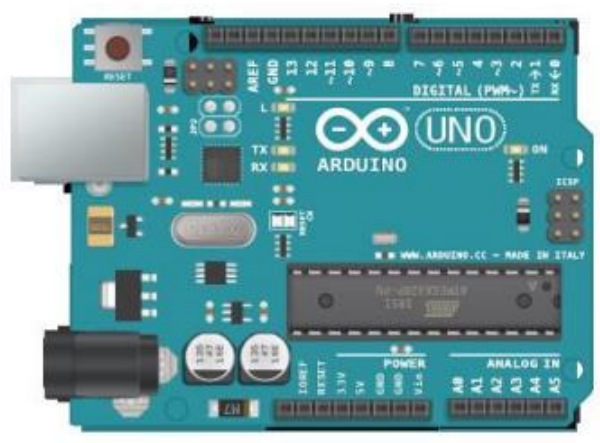

a Gambar 6. Arduino Uno

3. Perancangan Sistem

a. Cara Kerja Sistem berikut :

Secara keseluruhan, cara kerja dari sistem yang akan dibangun digambarkan melalui blok digram

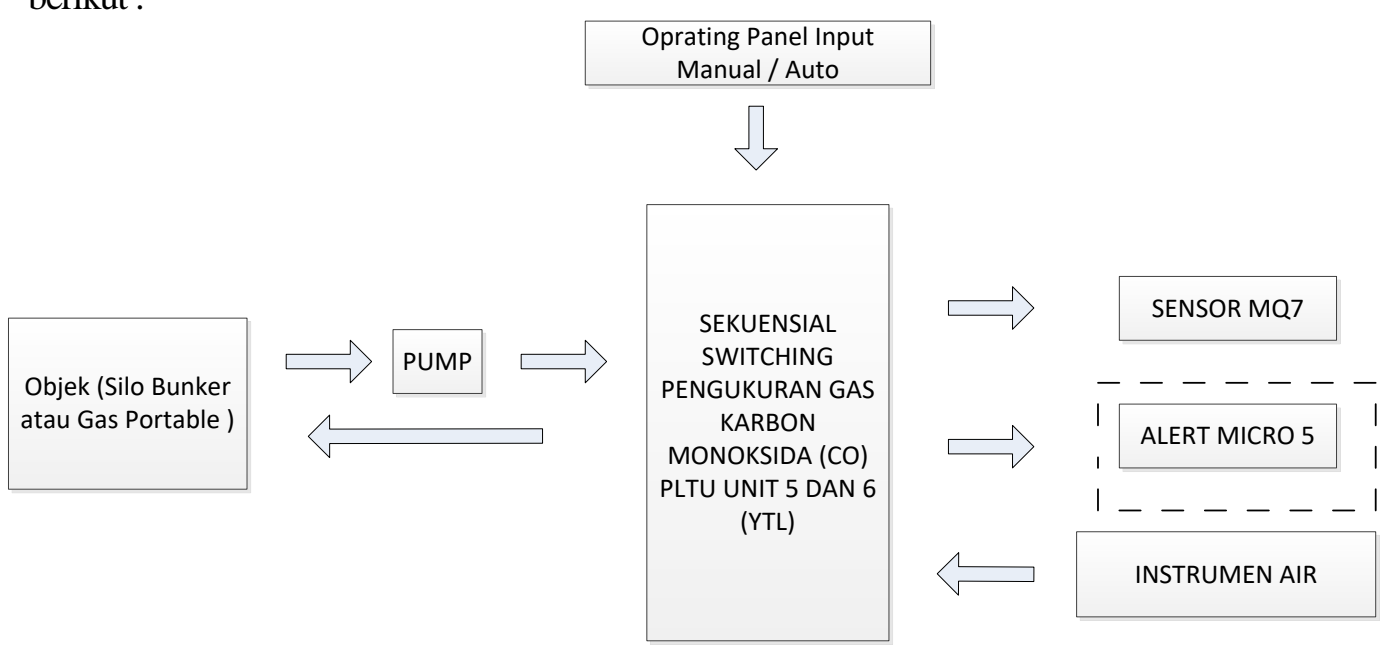

Gambar 7. Blok Diagram

Sistem sekuensial switching merupakan sistem kontrol sederhana yang menggunakan mikrokontroller dengan board Aruino Uno untuk memonitoring dan mengendalikan alat rancang bangun sekuensial switching pada silo bunker di PLTU. Blok diagram diatas menggambarkan switching pada pengukuran gas $\mathrm{CO}$ pada silo bunker yang dikontrol melalui mikrokontroller untuk mengaktifkan relay sehingga dapat menggerakkan coil pada 3 way solenoid valve dan mengaktifkan pump setelah solenoid 
aktif selama 3 detik untuk mengambil data gas $\mathrm{CO}$ yang terkandung dalam batu bara yang ditampung dalam silo bunker yang hasilnya dapat terbaca pada alat gas alert micro 5 atau sensor MQ-7.

Rancang bangun alat ini memiliki 3 buah 3 way solenoid valve sebagai media konektor, yaitu antara silo bunker dengan gas alert micro 5 atau sensor MQ-7, pump sebagai media untuk memaksimalkan pengambilan gas $\mathrm{CO}$ untuk disemprotkan pada sensor MQ-7 dan instrument air, sensor MQ-7 merupakan media untuk membaca gas $\mathrm{CO}$ sebagai pengganti gas alert micro 5 dan 3 modul relay yang mensimulasika fungsi saklar, yaitu memutus dan menyambung aliran listrik menuju 3 way solenoid valve.

b. Desain Kontrol Keseluruhan Sekuensial Switching Silo Bunker

Desain kontrol sekuensial switching silo bunker terdiri dari komponen utama untuk mengontrol proses kerja dari alat tersebut, yaitu arduino uno, relay, 3 way solenoid valve, power supplay 12 VDC, LCD I2C, sensor MQ-7 dan beberapa komponen untuk memberi perintah supaya control dapat bekerja sesuai dengan perintah yang dijalankan, yaitu selector 3 kaki sebagai perintah manual dan otomatis, selector 4 kaki sebagai perintah untuk mengaktifkan waktu 1,2,2.5 menit lama 3 way solenoid valve bekerja. Berikut adalah gambar sekuensial switching silo bunker :

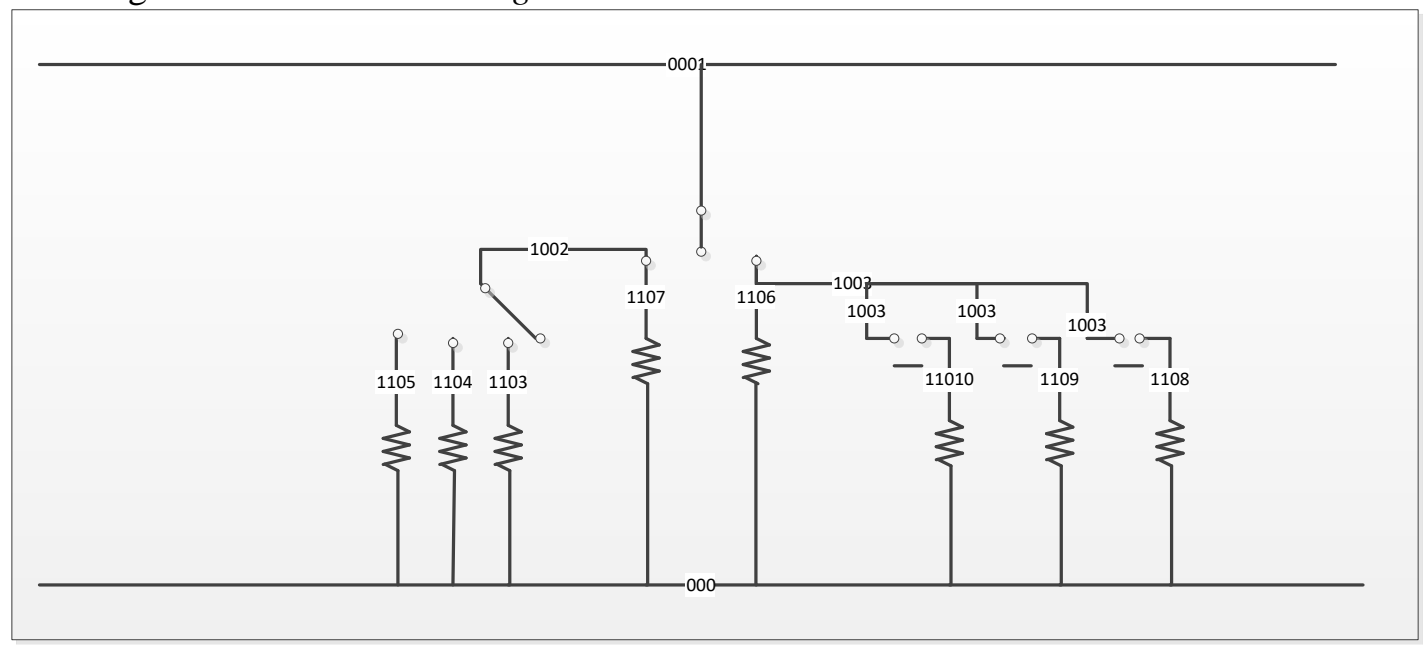

Gambar 8. Desain Kontrol 1

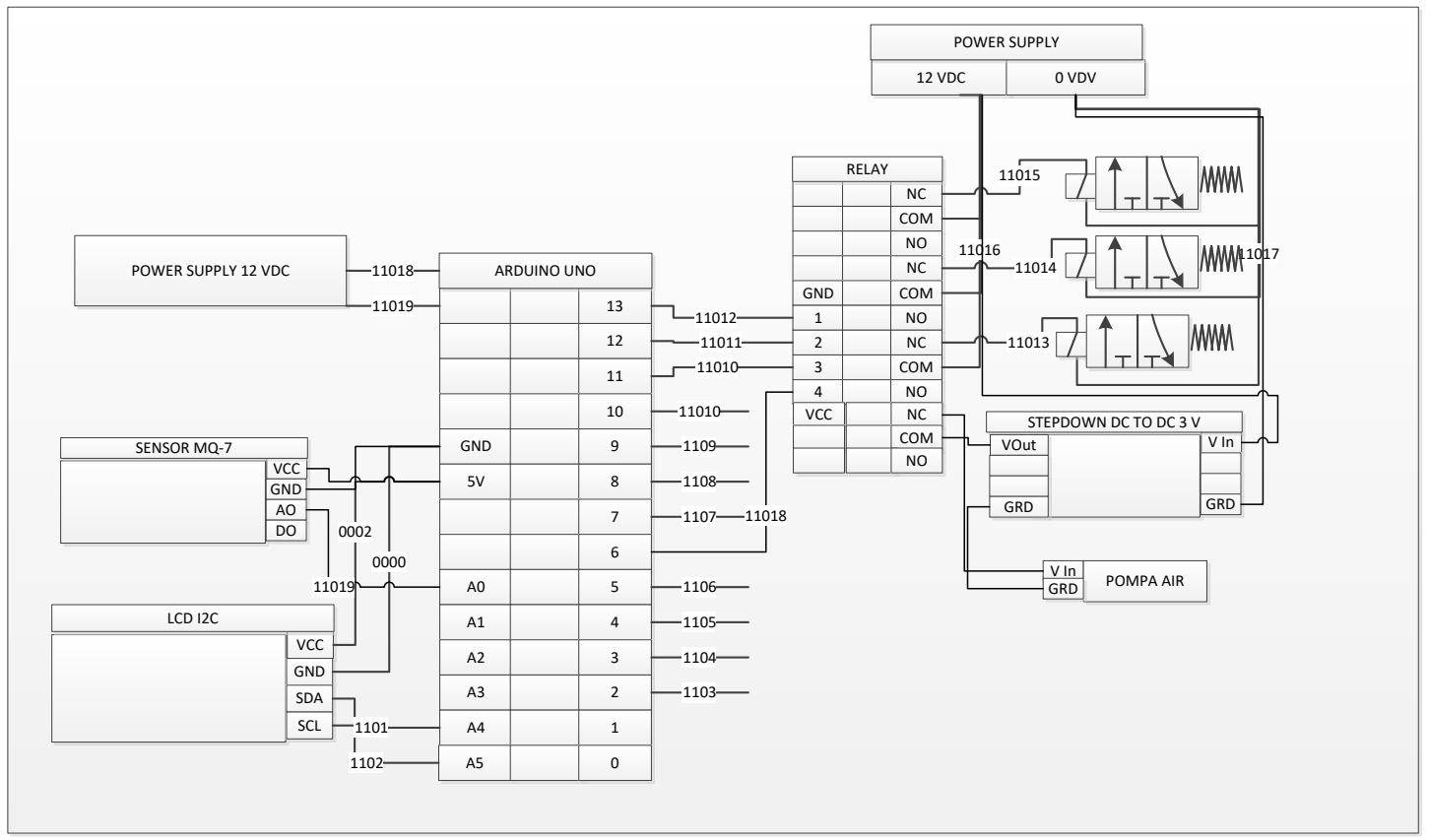

Gambar 9. Desain Kontrol 2 
PENGUJIAN DAN ANALISA

Pengujian dan analisa keseluruhan sistem dilakukan untuk mengetahui apakah hasil rancangan dapat bekerja sesuai atau tudak sesuai dari tujuan perancangan dibuat. Berikut gambar hasil dari perancangan yang sudah di desain dapat dilihat pada gambar dan gambar di bawah ini.

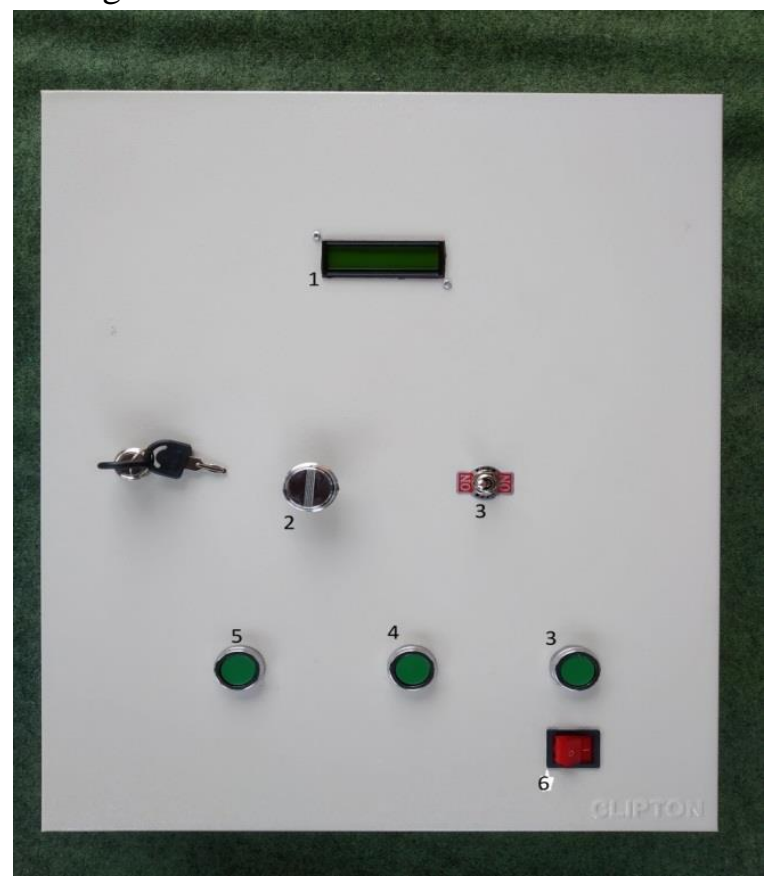

- Gambar 10. Hasil Alat Tampak Luar

- Tabel 1. Penjelasan Hasil Alat Tampak Luar

\begin{tabular}{ccc}
\hline NO & KOMPONEN & KETERANGAN \\
\hline 1. & LCD I2C & $\begin{array}{c}\text { Sebagai media untuk menampilkan kondisi yang } \\
\text { aktif dan hasil dari gas CO }\end{array}$ \\
2. & Selector 4 kondisi & Berfungsi sebagai pengaturan waktu 1 menit, 2 \\
menit, 2.5 menit
\end{tabular}




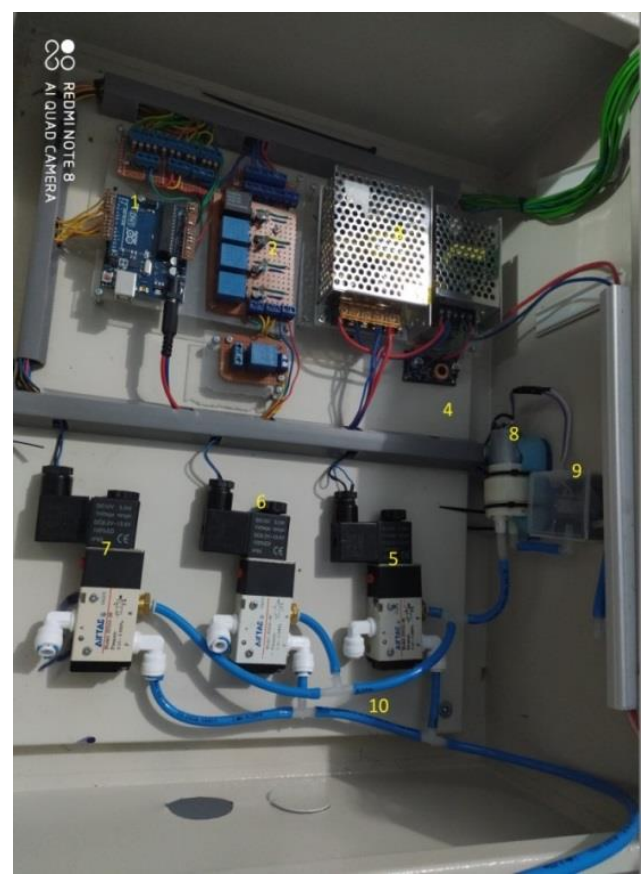

Gambar 11. Hasil Alat Tampak Dalam

Tabel 2. Penjelasan Hasil Alat Tampak Dalam

\begin{tabular}{|c|c|c|}
\hline $\mathrm{NO}$ & KOMPONEN & KETERANGAN \\
\hline 1. & Arduino Uno & Sebagai pusat control \\
\hline 2. & Relay & $\begin{array}{l}\text { Sebagai kontak untuk mengaktifkan } 3 \text { way } \\
\text { solenoid valve dan pump }\end{array}$ \\
\hline 3. & Power Supply 12 VDC & $\begin{array}{c}\text { Sumber tegangan } 220 \mathrm{VAC} \text { menjadi } 12 \mathrm{VDC} \\
\text { sebagai sumber tegangan pada komponen- } \\
\text { komponen }\end{array}$ \\
\hline 4. & Step Down DC TO DC & $\begin{array}{c}\text { Sebagai penuruntegangan dari 12VDC } \\
\text { menjadi 3VDC sebagai sumbertegangan } \\
\text { pump }\end{array}$ \\
\hline 5. & 3 way solenoid valve & $\begin{array}{c}\text { Sebagai terminal masuknya udara bertekanan } \\
\text { dan gas CO }\end{array}$ \\
\hline 6. & 3 way solenoid valve & $\begin{array}{c}\text { Sebagai terminal masuknya udara bertekanan } \\
\text { dan gas CO }\end{array}$ \\
\hline 7. & 3 way solenoid valve & $\begin{array}{l}\text { Sebagai terminal masuknya udara bertekanan } \\
\text { dan gas CO }\end{array}$ \\
\hline 8. & Pump & $\begin{array}{l}\text { Ssebagai menyedot dan menyemburkan gas } \\
\text { CO pada sensor }\end{array}$ \\
\hline 9. & Sensor MQ-7 & $\begin{array}{c}\text { Untuk membaca kandungan gas CO pada silo } \\
\text { bunker atau korek api }\end{array}$ \\
\hline 10. & Tubing & Sebagai konektor \\
\hline
\end{tabular}

1. Pengujian 3 way solenoid valve

Pengujian 3 way solenoid valve dilakukan untuk mengetahui hasil dari rancangan apakah sudah sesuai dengan prinsip kerja 3 way solenoid valve. Yaitu pada saat silo bunker $D$ aktif maka katup pada solenoid berada pada posisi (A ke R) dengan begitu katup pada solenoid silo bunker $E$ dan silo bunker $F$ berada pada posisi ( $\mathrm{P}$ ke A), pada saat silo bunker $E$ aktif maka katup pada solenoid berada pada posisi (A ke R) dengan begitu katup pada solenoid silo bunker $D$ dan silo bunker $F$ berada pada posisi (P ke A) dan begitupun pada saat silo bunker $F$ aktif maka katup pada solenoid berada pada posisi (A ke R) dengan begitu katup pada solenoid silo bunker $E$ dan silo bunker $D$ berada pada posisi (P ke A). 
Tabel 3. Hasil Pengujian 3 Way Selenoid Valve

\begin{tabular}{cccc}
\hline NO & KONDISI & P ke A & A ke R \\
\hline 1. & Manual Silo Bunker D Aktif & $\sqrt{ }$ & \\
2. & Manual Silo Bunker D Tidak Aktif & & $\sqrt{ }$ \\
3. & Manual Silo Bunker E Aktif & $\sqrt{ }$ & $\sqrt{ }$ \\
4. & Manual Silo Bunker E Tidak Aktif & $\sqrt{ }$ & \\
5. & Manual Silo Bunker F Aktif & & $\sqrt{ }$ \\
6. & Manual Silo Bunker F Tidak Aktif & & $\sqrt{ }$ \\
7. & Otomatis Silo Bunker D 1 Menit Aktif & & $\sqrt{ }$ \\
8. & Otomatis Silo Bunker E 1 Menit Aktif & & $\sqrt{ }$ \\
9. & Otomatis Silo Bunker F 1 Menit Aktif & & $\sqrt{ }$ \\
10. & Otomatis Silo Bunker D 2 Menit Aktif & & \\
11. & Otomatis Silo Bunker E 2,5 Menit Aktif & & \\
12. & Otomatis Silo Bunker F 2,5 Menit Aktif & & \\
\hline
\end{tabular}

2. Pengujian pump

Pengujian pump dilakukan untuk mengetahui hasil dari rancangan apakah sudah sesuai dengan penelitian. Yaitu pompa berfungsi untuk mempercepat aliran gas yang melewati tubing dan solenoid yang nantinya akan terbaca pada sensor MQ-7, pump akan aktif setelah 3 detik solenoid aktif. Berikut tabel hasi dari pengujian pump.

Tabel 4. Hasil Pengujian Pump

\begin{tabular}{cccc}
\hline NO & KONDISI & BAIK & TIDAK \\
\hline 1. & Manual Silo Bunker D Aktif & $\sqrt{ }$ & \\
2. & Manual Silo Bunker D Tidak Aktif & $\sqrt{ }$ & \\
3. & Manual Silo Bunker E Aktif & $\sqrt{ }$ & \\
4. & Manual Silo Bunker E Tidak Aktif & $\sqrt{ }$ & \\
5. & Manual Silo Bunker F Aktif & $\sqrt{ }$ & \\
6. & Manual Silo Bunker F Tidak Aktif & $\sqrt{ }$ \\
7. & Otomatis Silo Bunker D 1 Menit Aktif & $\sqrt{ }$ \\
8. & Otomatis Silo Bunker E 1 Menit Aktif & $\sqrt{ }$ \\
9. & Otomatis Silo Bunker F 1 Menit Aktif & $\sqrt{ }$ \\
10. & Otomatis Silo Bunker D 2 Menit Aktif & $\sqrt{ }$ \\
11. & Otomatis Silo Bunker E 2,5 Menit Aktif & $\sqrt{ }$ & \\
12. & Otomatis Silo Bunker F 2,5 Menit Aktif & $\sqrt{ }$ & \\
\hline
\end{tabular}

3. Pengujian sensor MQ-7

Pengujian sensor berfungsi untuk mengetahui nilai gas yang melewati solenoid dari silo bunker menuju sensor. Sensor hanya sebagai media apakah gas $\mathrm{CO}$ dapat melewati solenoid atau tidak.

Tabel 5. Hasil Pengujian Sensor MQ-07

\begin{tabular}{ccc}
\hline NO & KONDISI & HASIL GAS CO \\
\hline 1. & Otomatis Silo Bunker D 1 Menit & 8.22 PPM \\
2. & Otomatis Silo Bunker E 1 Menit & 14.66 PPM \\
3. & Otomatis Silo Bunker F 1 Menit & 11.71 PPM \\
4. & Otomatis Silo Bunker D 2 Menit & 6.10 PPM \\
5. & Otomatis Silo Bunker E 2 Menit & 17.37 PPM \\
6. & Otomatis Silo Bunker F 2 Menit & 9.41 PPM \\
7. & Otomatis Silo Bunker D 2,5 Menit & 5.44 PPM \\
\hline
\end{tabular}




\begin{tabular}{ccc}
\hline 8. & Otomatis Silo Bunker E 2,5 Menit & $13.21 \mathrm{PPM}$ \\
9. & Otomatis Silo Bunker F 2,5Menit & 11.57 PPM \\
10. & Manual Silo Bunker D & $16.69 \mathrm{PPM}$ \\
11. & Manual Silo Bunker E & 7.88 PPM \\
12. & Manual Silo Bunker F & $4.53 \mathrm{PPM}$ \\
13. & Otomatis & $1.19 \mathrm{PPM}$ \\
14. & Manual & $1.19 \mathrm{PPM}$ \\
\hline
\end{tabular}

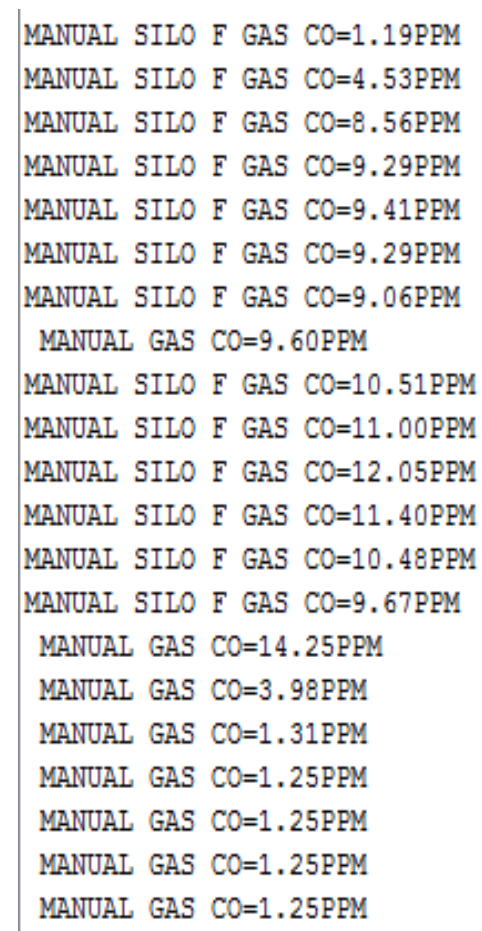

- Gambar 12. Hasil Pengujian Ditampilkan pada Serial Monitor

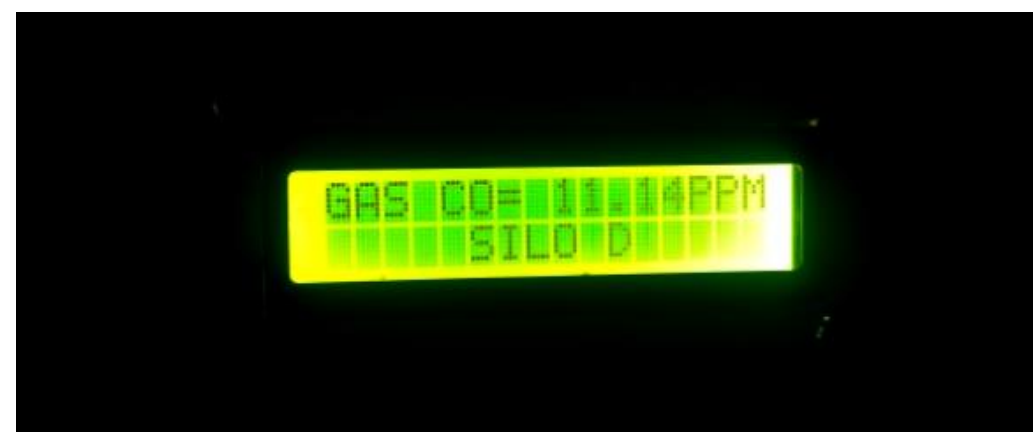

- Gambar 13. Hasil Pengujian Ditampilkan pada LCD I2C

\section{KESIMPULAN DAN SARAN}

Berdasarkan hasil dari pengujian keseluruhan alat yang berjudul "Rancang Bangun Sekuensial Switching untuk Pengukuran Gas Karbon Monoksida (CO) pada Silo Bunker di PLTU Unit 5 dan 6 Paiton" diperoleh kesimpulan bahwa pada saat silo bunker $D$ diaktifkan maka katup pada valve $(A$ ke $R$ ) akan terbuka untuk mengambil sample gas $\mathrm{CO}$ dan katup valve ( $P$ ke A) pada silo bunker $E$ dan $F$ akan terbuka untuk dimasukkan instrumen air supaya dapat membersihan sisa-sisa gas $C O$ dan debu agar tidak tersumbat pada tubing. 3 way solenoid valve dapat bekerja hanya dengan menggunakan udara yang bertekanan.

Saran untuk pengembangan lebih lanjut dari alat yang berjudul "Rancang Bangun Sekuensial Switching untuk Pengukuran Gas Karbon Monoksida (CO) pada Silo Bunker di PLTU Unit 5 dan 6 Paiton" sebagai berikut :

- Penggunaan 3 way selenoid valve tanpa menggunakan udara yang bertekanan, agar dapat 
memaksimalkan cara kerja 3 way selenoid valve.

- Kedepannya alat tersebut dapat memasukkan gas $\mathrm{CO} 2$ secara otomatis dan

- Dapat dikendalikan dari jarak jauh.

\section{DAFTAR PUSTAKA}

[1] A. I. R. Liquide, "Carbon monoxide Carbon monoxide," Saf. Data Sheet, pp. 1-15, 2018.

[2] Dandi Nugroho and Sunarto, "MODIFIKASI OUTLET COALBUNKER DAN OUTLET COAL FEEDER UNTUK MENGATASI PLUGGING BATUBARA DI PLTU TANJUNG AWAR-AWAR TUBAN," Keilmuan dan Terap. Tek., vol. 06, pp. 48-54, 2017.

[3] A. S. Ramadhani, "Sistem Emergency Shut Down ( ESD ) pada Hydrocracking Unit A ( HCUA ) di PT . Pertamina ( Persero ) Refinery Unit V ( RU V ) Balikpapan," Tek. elektro, vol. 1, pp. 1-9, 2019.

[4] P. A. Wirananda, "LAPORAN KERJA PRAKTIK di PT. YTL Jawa Timur Jl. Raya Surabaya - Situbondo Km 141, Paiton, Probolinggo, Jawa Timur," 2016.

[5] N. Fidelia, "SISTEM PEMANTAUAN KUALITAS UDARA MENGGUNAKAN PETA DIGITAL BERBASIS SENSOR KARBON MONOKSIDA BERGERAK," 2017.

[6] A. W. Yudha, "PERANCANGAN SISTEM PENGATURAN TEKANAN PADA SHUTDOWN VALVE UNTUK ANTISIPASI KEBAKARAN BERBASIS PNEUMATIC MENGGUNAKAN MIKROKONTROLER ATMEGA 328," pp. 1-10, 2015.

[7] M. A. Nugroho, "Rancang bangun sistem supervisory control and data acquisition (scada) pada gardu induk pln berbasis mikrokontroller skripsi," 2019. 